\title{
2. Economics
}

\author{
R. Quentin Grafton \\ The Australian National University, Australia
}

The economics of water concerns the measurement and effective management of the trade-offs across its many competing uses (and non-uses) over time and in different locations. Measurement requires estimation of the costs, benefits and risks associated with alternative uses of water. For example, these alternatives could be: (i) keeping water in the river to support ecosystem services, (ii) extracting it for a town's water supply, or (iii) using water to irrigate a rice crop. Effective management ensures that society's objectives for water use (for example, environmental sustainability, sanitation and waste disposal, or food production) are achieved by supporting methods to allocate water that favours higher value uses (including non-uses) and ensures that basic water needs are met.

\section{Measuring the value of water}

The challenge of measuring the value of water across different settings is that it is used as an input or intermediate good in many production systems and, thus, has multiple and possibly competing values as a factor of production. But water can also be a final product, such as drinking water, washing, or waste disposal, and also has value in situ, such as when water is not extracted from a river to generate or retain ecosystem services and benefits. The market benefits of water in production processes or direct use can be determined from market transactions, such as the price at which water is traded in a market or water's derived demand in the production of a crop or product.

Typically, the greater challenge is to estimate water's value in a setting where markets, in general, do not exist and there is no direct production beyond ecosystem services. Non-market valuation techniques that can, and have, been employed include: (1) valuing recreational sites and rivers by the travel costs of those who make use of ecosystems services, such as catching fish or canoeing; and, (2) stated preference methods whereby people are asked direct questions about their willingness to pay for a change in the quantity and quality of a water resources. In both travel cost and stated preference approaches the values obtained from respondents are, in general, aggregated to obtain an aggregate valuation from water. 


\section{Managing trade-offs}

Valuations and values of water provide the basis for allocating water efficiently and equitably across competing uses and users. Typically, economists use a costbenefit analysis (CBA) framework that also accounts for risk and enables the comparison of alternative allocations across competing uses. The typical rule is that any allocation should generate a positive net present value such that the 'discounted benefits' ${ }^{1}$ of the given allocation, less the discounted costs, is positive. Ideally, allocations with higher benefit-to-cost ratios are preferred. For this tool to be useful all costs and benefits must be accounted for, including the hard-to-measure non-market values for water and especially water in situ.

While CBA is a helpful economic tool to manage trade-offs, decisions about reallocating water across competing uses must also involve consideration of equity, or who gets what and when. Thus, an allocation that makes disadvantaged or vulnerable groups worse off, and without adequate compensation, may not be desirable from a societal or fairness perspective, even if the allocation has a high costs-benefit ratio for society as a whole.

Beyond the calculation of costs, benefits and compensation arising from changes in water allocations, effectively managing trade-offs also requires an understanding of water externalities. This is an economic term for spillovers, both positive and negative, that arise from the actions of water users or keeping water in situ, and which are not accounted for in the decision-making of an individual water user. For example, a farmer irrigating a crop may impose externalities on downstream irrigators if the upstream farmer's river extraction reduces water availability downstream. In the case of recreational users, the externality could be that the water returned to the river after irrigation use is of lower quality. If the upstream irrigator does not account for these downstream costs then too much water will be used in irrigation upstream. This is a common cause of environmental problems and is a major driver of the overuse of water.

Another challenge in water use is that water management can provide non-rival benefits or public good benefits. These benefits can be enjoyed by all, such as the aesthetic and ecosystem benefits of wild rivers, but can be underprovided because of 'free riders' who enjoy, but do not wish to pay for, these benefits. Typically, local, regional, or even national governments intervene to provide the public good benefits of water, but even so under-provision remains common.

1 The term 'discounted benefits' implies that benefits felt in the longer term receive a lower weighting in cost-benefit calculations. So longer term benefits are significantly 'discounted' when we think about them in terms of their 'present value'. This method for adding up costs and benefits over a period of time is a common technique in economics and, indeed, in the daily consumption and production decisions that we all make. 
The key to managing trade-offs is to devise effective methods to overcome under-provision of the public benefits of water and prevent the overuse of water in cost-effective ways. These may include: cap and trade markets for water to reduce overuse, water emission taxes to reduce water pollution and user charges to recoup public benefits of use.

\section{Overview of chapters}

The economics section of this volume has six chapters covering a broad range of issues. The articles provide insights into the application of economics to the measurement and management challenges discussed above. Ward and White (Chapter 3) summarise the key findings of a paper published in Water Resources Research showing how and the level at which households in Organisation for Economic Co-operation and Development (OECD) countries are charged for their water effects their consumption and behaviour. Rodriguez and McMahon (Chapter 4), both of the World Bank, review the financing of water supply and sanitation in developing countries. Their key insight is that while financing is a critical issue, the management of water providers and the incentives that they operate under are equally as important to ensure delivery of cost effective water services, especially to the poor and vulnerable. Abramson and Gurin (Chapter 5) take a micro view of how farmers and households in poor countries can access adequate water given that they do not have access to centralised systems and must obtain water by their own means. While hand-operated water pumps are ubiquitous, they are insufficient for the needs of households and farmers, and powered pumps offer substantial benefits to the water-deprived. Katic's chapter on water use by West African rice farmers (Chapter 6) emphasises that simply increasing water supplies does not necessarily raise incomes. While greater water availability raises yields and revenues, these can be offset by higher costs. Importantly, she finds that there are other ways to boost farm revenues such as improvements in the quality of local produce. Kajisa (Chapter 7) examines the growing use of private pumps and wells in Tamil Nadu, India and its impact on community-based and managed irrigation systems. Lower cost pumps have allowed individual farmers to benefit from accessing groundwater in their own wells, but at a social cost. This has imposed a 'double tragedy': the depletion of groundwater systems and a reduction of investment and effectiveness in community-based systems, which leaves poorer farmers, who have been less able to build and use their own wells, much worse off. The last chapter in this section, by Grafton and Horne (Chapter 8), is based on work published in Agricultural Water Management. They describe the history, net benefits and limitations of water markets in the Murray-Darling Basin. Their contribution 
shows how water markets can in practice, and not just in theory, provide a means to improve outcomes for water users and a means to reallocate water from use to non-use purposes.

Dr R. Quentin Grafton FASSA is Professor of Economics, ANU Public Policy Fellow and Director of the Centre for Water Economics, Environment and Policy (CWEEP) at the Crawford School of Public Policy at The Australian National University. He is the Chairholder, the UNESCO Chair in Water Economics and Transboundary Water Governance and in August 2013 was appointed Executive Director at The Australian National Institute of Public Policy (ANIPP). 
This text taken from Global Water: Issues and Insights by R. Quentin Grafton, Paul Wyrwoll, Chris White and David Allendes, published May 2014 by ANU Press, The Australian National University, Canberra, Australia. 